\title{
The Effect of Glucose and Galactose Toxicity on Myo-inositol Transport and Metabolism in Human Skin Fibroblasts in Culture
}

\author{
G. T. BERRY, J. E. PRANTNER, B. STATES, AND J. R. YANDRASITZ \\ Division of Biochemical Development and Molecular Diseases, Department of Pediatrics, University' of \\ Pennsylvania School of Medicine and The Children's Hospital of Philadelphia. Philadelphia. Pennsylvania 19104
}

\begin{abstract}
Myo-inositol transport and metabolism were studied in cultured human skin fibroblasts exposed to potentially toxic levels of glucose or galactose. Although variable among 11 different cell lines, the myo-inositol level in confluent cells, ranging from $10-50 \mathrm{nmol} / \mathrm{mg}$ protein, was constant with passage. A high-affinity transport system for myo-inositol had an apparent $K_{t}$ of $55 \mu \mathrm{M}$ and $V_{\max }$ of $16 \mathrm{pmol} / \mathrm{min} / \mathrm{mg}$ protein. No obvious relationship existed between cellular levels and transport capacity. Dependency on sodium was complex. When medium sodium was lowered to $23 \mathrm{mM}$, myo-inositol uptake ceased after about $1 \mathrm{~h}$. However, the initial rate of myo-inositol uptake only showed a sodium dependence at low myo-inositol concentrations. Both phloretin and phloridzin inhibited myo-inositol uptake. Phloridzin had a $K_{i}$ of $60 \mu \mathrm{M}$, and phloretin was either a noncompetitive or uncompetitive inhibitor. Glucose and galactose were only weak competitive inhibitors, with a $K_{i}$ of $30 \mathrm{mM}$ and $65 \mathrm{mM}$, respectively. After $24 \mathrm{~h}$ of incubation with myo- $\left[2-{ }^{3} \mathrm{H}\right]$ inositol, only $10 \%$ of the total cell label was incorporated into phospholipid. Compared with control media with $5 \mathrm{mM}$ glucose, the incubation of confluent cells in media with $\mathbf{2 0}$ $\mathrm{mM}$ glucose had little effect on intracellular glucose and sorbitol, whereas cells incubated in control media supplemented with $5 \mathrm{mM}$ galactose showed a large increase in galactose and polyol levels. In media with more than $\mathbf{2 0 0}$ $\mu \mathrm{M}$ of myo-inositol, neither treatment had an effect on myo-inositol levels after $24 \mathrm{~h}$. The uptake and incorporation of $11 \mu \mathrm{M} m y o-\left[2-{ }^{3} \mathrm{H}\right]$ inositol and incorporation into phospholipid were studied after cells had been previously exposed for 24 to $48 \mathrm{~h}$ to media supplemented with $15 \mathrm{mM}$ glucose or galactose. Compared with controls, fibroblasts with a 24-h exposure to $20 \mathrm{mM}$ glucose showed a $10 \%$ decrease in myo-inositol uptake. When the exposure was extended to $48 \mathrm{~h}$, preconditioning with galactose as well as glucose elicited the same $10 \%$ reduction in uptake. Phosphoinositide labeling in fibroblasts exposed to $20 \mathrm{mM}$ glucose was reduced in parallel. These cells offer a unique opportunity for the study of sugar toxicity in human tissue: they can be exposed to high levels of glucose without significant glucose or polyol accumulation or can be made to accumulate polyol by exposure to moderate levels of galactose. The expression of a hexose-induced reduction in myo-inositol transport required 24 to $48 \mathrm{~h}$ of exposure of the fibroblasts to elevated concentrations of glucose or galactose and may not be related to a competitive inhibitory
\end{abstract}

Received July 13, 1993; accepted September 27, 1993

Correspondence: Gerard T. Berry, M.D., Division of Biochemical Development and Molecular Diseases. The Children's Hospital of Philadelphia, 34th Street \& Civic Center Boulevard. Philadelphia. PA 19104

Supported by National Institutes of Health Grant Number DK 40382. effect of these sugars on transport. (Pediatr Res 35: 141147, 1994)

\author{
Abbreviations \\ MEM, minimum essential medium with Earle's balanced \\ salts \\ FBS, fetal bovine serum \\ $K_{t}$, solute concentration that yields transport velocity equal \\ to one half the $V_{\max }$ \\ $K_{i}$, inhibitor concentration that will decrease $V_{\max }$ by one \\ half
}

Myo-inositol is an important cell constituent because it is the precursor of a plasma membrane phospholipid, which on agonist-stimulated degradation yields both a water-soluble and lipid product that are key informational molecules in one class of signal transduction mechanisms $(1,2)$. In most mammalian cells or tissues, the content of myo-inositol is 5- to 500-fold higher than the level in plasma or extracellular fluid, with active transport system(s) for myo-inositol responsible for the maintenance of these concentration gradients $(3,4)$. Whether myo-inositol must be maintained within a critical range in most cells to allow for adequate synthesis of phosphatidylinositol, the most abundant $m y o$-inositol-containing phospholipid, remains to be determined. However, the level of myo-inositol has been found to be reduced in certain tissues of the experimental diabetic animal, which in the patient with diabetes mellitus represent the target tissues that are associated with both diabetic complications and the accumulation of the polyol sorbitol (5). Abnormal myoinositol metabolism has been suggested as playing a role in the pathogenesis of the late complications of diabetes mellitus, perhaps as a consequence of diminished synthesis of phosphatidylinositol $(5,6)$.

Cultured cells have been used to model the metabolic milieu of diabetes mellitus and in particular to study the effect of hyperglycemia alone. In retinal capillary pericytes (7), cultured neuroblastoma cells (8), retinal pigment epithelial cells $(9,10)$, cultured aortic endothelial cells (11), and glomerular mesangial cells (12), glucose in high concentrations may act as a competitive or noncompetitive inhibitor of myo-inositol uptake, and extended exposure of the cells to elevated levels of glucose may lead to a reduction in cell myo-inositol content $(8,10-13)$. Galactose is at best a very weak competitive inhibitor of myoinositol uptake, but prolonged exposure to elevated levels of galactose has also been shown to produce "diabetic-like" abnormalities in myo-inositol metabolism in cultured cells (14). A reduction in tissue myo-inositol content has been detected in experimental animals rendered hypergalactosemic (15), a model 
that produces several pathophysiologic abnormalities reminiscent of the diabetic state.

The reduction in cellular myo-inositol levels that accompanies incubations with high levels of glucose or galactose may be at least partially prevented by concomitant treatment with an inhibitor of aldose reductase $(7,10,12,14)$, suggesting that the synthesis and accumulation of polyol may be responsible, at least in part, for the alterations in myo-inositol metabolism.

However, the use of cultured cells to study the effects of glucose or galactose on myo-inositol metabolism has yielded conflicting results (13). Even in the experimental diabetic animal, paradoxical changes in myo-inositol levels have been detected in certain tissues on prolonged exposure to hyperglycemia (16). One of the underlying assumptions of the polyol toxicity hypothesis in diabetes mellitus is that the "target cells" exposed to elevated extracellular glucose levels as a consequence of hyperglycemia must accumulate glucose intracellularly because of the presence of noninsulin-dependent facilitated glucose diffusion and a ratelimiting glucokinase activity. As a consequence, cells that are relatively enriched in one or more aldehyde oxidoreductases, such as aldose reductase, will accumulate sorbitol resulting from activation of the polyol pathway. We reasoned that fibroblasts would be uniquely suited for examination of the polyol hypothesis because their capacity to transport glucose is thought to be weak and increased polyol pathway activity is dependent on intracellular glucose levels. Evidence shows that human fibroblasts express an energy and sodium-dependent high-affinity transporter for myo-inositol that may be regulated by a gene on the long arm of chromosome 21 (17). According to the hypothesis, myo-inositol deficiency would probably only develop in fibroblasts exposed to elevated glucose concentrations if extracellular glucose were to act as a strong competitive inhibitor of myo-inositol transport and that under these circumstances the use of mammalian fetal serum-like concentrations of extracellular myo-inositol would eliminate the expression of the deficiency state. Alternatively, because investigators have demonstrated that human skin fibroblasts readily take up galactose and convert it to galactitol (18), exposure to elevated galactose concentrations might result in the development of a myo-inositol deficiency in the absence of a glucose effect because the mechanism might involve the polyol pathway selectively and not competitive inhibition. To answer these questions, we first delineated the nature of myo-inositol transport in human skin fibroblasts and then examined the effects of elevated glucose or galactose concentrations on myo-inositol metabolism.

\section{MATERIALS AND METHODS}

Cell culture. Human fibroblasts were grown in our cell culture facility after procurement of biopsy samples from 11 individuals with no identifiable genetic diseases. The biopsies were performed at the time of an elective herniorrhaphy in seven males and two females who were 2 mo to 13 y of age. One 9-y-old female underwent excision of a cardiac tumor, and a 5-y-old male had idiopathic mental retardation and asthma. Fibroblasts were grown in $25-\mathrm{cm}^{2}$ flasks in MEM (JRH Biosciences, Lenexa, $\mathrm{KS}$ ) supplemented with $2 \mathrm{mM}$ glutamine and containing $20 \%$ FBS (Whittaker Bioproducts, Walkersville. MD). They were incubated at $37^{\circ} \mathrm{C}$ in $5 \% \mathrm{CO}_{2}$ in air as described by States $\mathrm{et}$ al. (19). Cultures were passed weekly and used at confluence. They were refed $1 \mathrm{~d}$ before the experiments. Most lots of FBS contain about $1 \mathrm{mM}$ myo-inositol. In these experiments the myo-inositol concentration in MEM supplemented with $20 \%$ FBS was $224 \pm$ $6 \mu \mathrm{M}(n=36)$.

Transport studies. Experiments on the uptake of $m_{y} \%-\left[2-{ }^{3} \mathrm{H}\right]$ inositol were performed in MEM without serum to which was added a sterile mixture of $m y o-\left[2-{ }^{3} \mathrm{H}\right]$ inositol and ${ }^{14} \mathrm{C}$-polyethylene glycol 4000 with a tracer ratio of about $5: 1$. For concentration dependence experiments, varying amounts of a sterile 50 $\mathrm{mM}$ myo-inositol stock solution were added; the amount of label was increased at the higher concentrations of myo-inositol to partially offset the reduction in specific activity. For experiments testing the effects of elevated sugar levels, aliquots of sterile solutions of $0.5 \mathrm{M}$ glucose or galactose were added to the medium. For sodium dependence studies, the media were prepared by mixing normal MEM with MEM in which the $\mathrm{NaCl}$ had been replaced by choline chloride (GIBCO Laboratories, Grand Island, NY).

Flasks were removed from the incubator to initiate the incubation. The medium was gently aspirated, $4-5 \mathrm{~mL}$ of fresh medium containing isotopes and additions were added, and the flasks were returned to the incubator for the indicated times. Phloridzin or phloretin was added as $50 \mathrm{mM}$ solutions in $50 \%$ ethanol. Ethanol alone up to $1 \%$ had no effect on the uptake of $m ! o-\left[2-{ }^{3} \mathrm{H}\right]$ inositol.

At the end of the incubation, the medium was removed, and cells were washed twice with PBS at room temperature. Cells were lysed by adding $2 \mathrm{~mL}$ of ice-cold water and placing the flasks on ice for at least $1 \mathrm{~min}$. The contents were scraped and transferred to tubes along with a $2-\mathrm{mL}$ water rinse. For gas-liquid chromatography studies an internal standard of $20 \mathrm{nmol}$ each of ribitol and $\alpha$-methylmannopyranoside were added. Samples of the suspension were taken for determination of protein. The remainder was centrifuged at $40000 \times g$ for $15 \mathrm{~min}$ at $4^{\circ} \mathrm{C}$. The supernatant was recovered, and either a portion was counted directly or the entire fraction was evaporated in a vacuum oven at $40^{\circ}$ for liquid scintillation counting. For determination of incorporation of $m y()-\left[2-{ }^{3} \mathrm{H}\right]$ inositol into lipid, the pellet was washed once by resuspending in $4 \mathrm{~mL}$ of cold water and recentrifuged.

Samples were counted in ACS-II containing $10 \%$ water or in BCS containing $5 \%$ water. Triplicate $10-\mu \mathrm{L}$ samples of the labeled incubation media were counted to obtain a ${ }^{14} \mathrm{C} /{ }^{3} \mathrm{H}$ ratio for calculation of trapped extracellular space and to calculate the specific activity of the myor $\left[2-{ }^{3} \mathrm{H}\right]$ inositol using the known concentration of my(o-inositol in the medium.

Metabolite levels. Gas-liquid chromatography was used to quantitate myo-inositol, the polyols, sorbitol or galactitol, and the carbohydrates, glucose and galactose. Samples were dried under $\mathrm{N}_{2}$ and trimethylsilyl derivatives formed by stirring overnight with $80 \mu \mathrm{L}$ of mixture consisting of pyridine/ bis(trimethylsilyl)trifluoroacetamide/trimethylchlorosilane in a ratio of $1: 1: 0.05$. Chromatography was performed using a PerkinElmer model 3920 with flame ionization detector (Perkin-Elmer, Norwalk, CT). Separations were accomplished using a 6 -foot $x$ 4-mm glass column packed with 3\% SP-2100 on Supelcoport (Supelco, Bellafonte, PA).

Protein was measured by the method of Lowry et al. (20). Except as noted, chemicals were from Sigma Chemical Co. (St. Louis, MO). Myo-[2- $\left.{ }^{3} \mathrm{H}\right]$ Inositol, ${ }^{14} \mathrm{C}$-polyethylene glycol 4000 , and liquid scintillation mixtures (ACS-II and BCS) were obtained from Amersham Corp. (Arlington Heights, IL). Kinetic parameters were derived by nonlinear least-squares regression analyses of data using SigmaPlot version 4 (Jandel Scientific, Corte Madera, CA). The $t$ test was used to compare uptake rates, phosphatidylinositol biosynthetic rates, and metabolite levels.

\section{RESULTS}

The time course for uptake of several concentrations of myeinositol is shown in Figure 1. Uptake was found to be linear with time for the first $5 \mathrm{~h}$ (insert) but began to slow by $24 \mathrm{~h}$. We therefore used uptake at 30 to $120 \mathrm{~min}$ to further characterize my(o-inositol transport. The incorporation of $m y()-\left[2-{ }^{3} \mathrm{H}\right]$ inositol into fibroblast lipid was also examined in these experiments, and the data are presented in Figure 2. Very little label appeared in lipid during the first $30 \mathrm{~min}$ of incubation, but incorporation was then linear from 5 to $48 \mathrm{~h}$. Most of the fibroblast my-[2${ }^{3} \mathrm{H}$ ]inositol remained in the soluble pool, with less than $10 \%$ of the total found in membranes after $24 \mathrm{~h}$. In a few experiments 


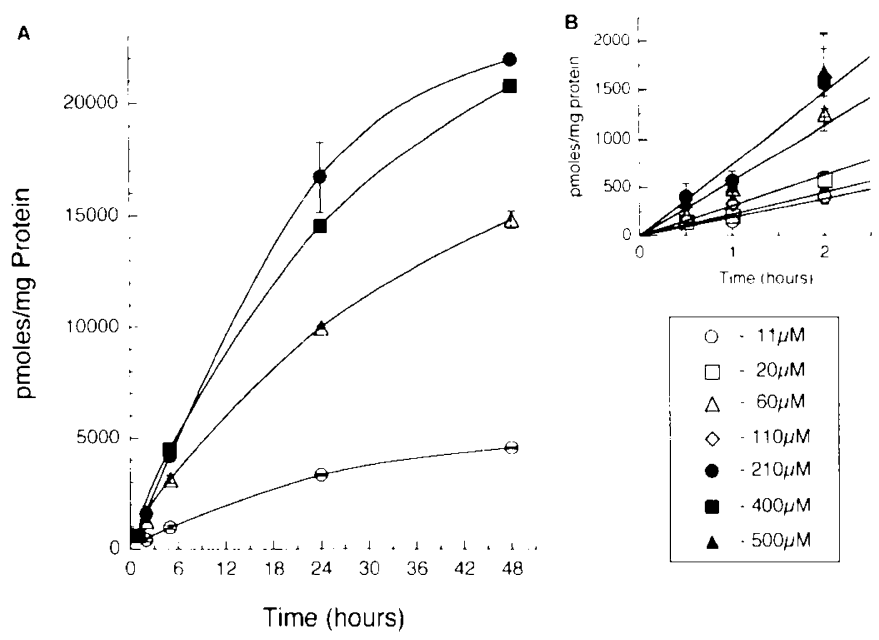

Fig. 1. Time course of $m y \cdot-\left[2-{ }^{3} \mathrm{H}\right]$ inositol uptake by human skin fibroblasts. Fibroblasts were incubated for the indicated times in $25-\mathrm{cm}^{2}$ flasks in MEM without serum containing varying concentrations of myo[2- $\left.{ }^{3} \mathrm{H}\right]$ inositol. Myo-inositol uptake was calculated in picomoles by the specific radioactivity of the medium. Results are the means \pm SEM for two to eight determinations.

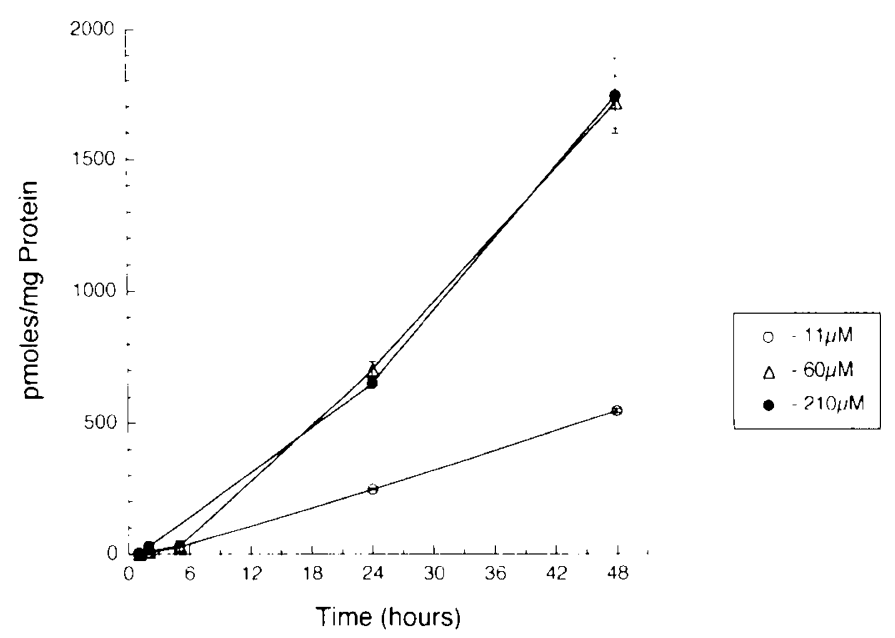

Fig. 2. Time course of incorporation of myor $\left[2-{ }^{3} \mathrm{H}\right]$ inositol into phospholipid by human skin fibroblasts. Fibroblasts were incubated as in Figure 1 . The cells were lysed with water, the extract was centrifuged at $40000 \times g$ for $15 \mathrm{~min}$, and the pellet washed and counted.

the membrane pellets were extracted and lipids separated by thin-layer chromatography. Essentially all of the label was found in phosphatidylinositol. If the incubation was stopped with cold trichloroacetic acid rather than water, label could also be found in polyphosphoinositides, but this amount was only a few percent of the label in phosphatidylinositol.

The concentration dependence of myo-inositol transport was determined in experiments using 11 to $400 \mu \mathrm{M} \mathrm{my}$ o-inositol and incubation times of $30 \mathrm{~min}$ to $2 \mathrm{~h}$. This concentration range was chosen because the focus of this study was on the effects of sugar toxicity on the physiologically relevant high-affinity transport system. Fitting the data to a Michaelis-Menten equation revealed a $\mathrm{V}_{\max }$ of $15.8 \pm 0.9 \mathrm{pmol} / \mathrm{min} / \mathrm{mg}$ protein and an apparent $\mathrm{K}_{t}$ of $55 \pm 9 \mu \mathrm{M}$.

The effect of medium sodium concentration on uptake of 11 $\mu \mathrm{M}$ and $110 \mu \mathrm{M} \mathrm{my}$ (-inositol with time is shown in Figures $3 A$ and $3 B$, respectively. Reduction of sodium concentration from 134 to $67 \mathrm{mM}$ had little effect on uptake at either myo-inositol concentration for up to $120 \mathrm{~min}$. However, with only $23 \mathrm{mM}$ sodium in the bathing medium the transport of myo-inositol was significantly reduced at longer times. The permeability charac-
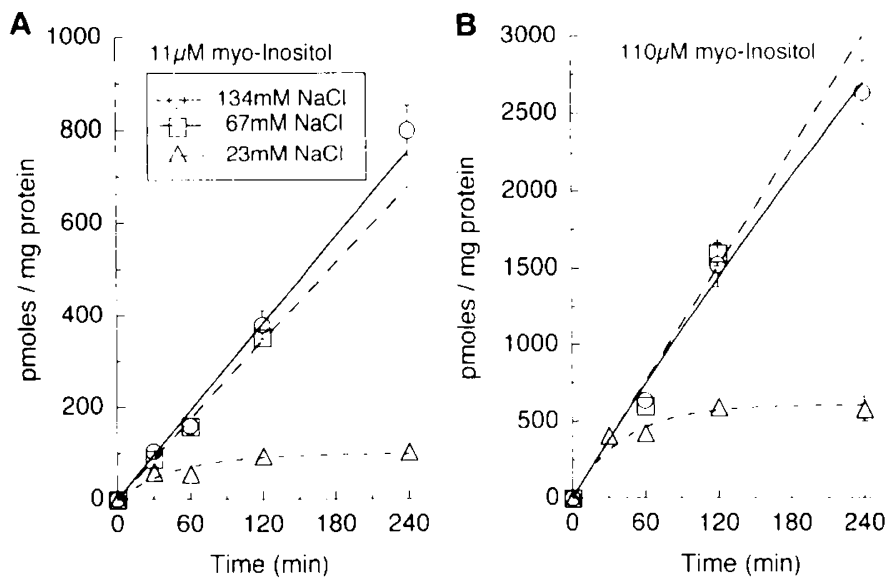

Fig. 3. Time course of the uptake of mer $\left[2 \cdot{ }^{3} \mathrm{H}\right]$ inositol at varying concentrations of sodium. Fibroblasts were incubated with m.ro- $\left[2-{ }^{3} \mathrm{H}\right]$ inositol at $11 \mu \mathrm{M}(.1)$ or $110 \mu \mathrm{M}(B)$ in mixtures of normal MEM and MEM in which $\mathrm{NaCl}$ was replaced by choline chloride to give sodium concentrations of 23 to $134 \mathrm{mM}$. Uptake of my (r-inositol was determined at varying times from 30 to $240 \mathrm{~min}$. The data presented are means \pm SEM for two to eight determinations. The lines were calculated by nonlinear regression analysis assuming a first-order dependence with time.

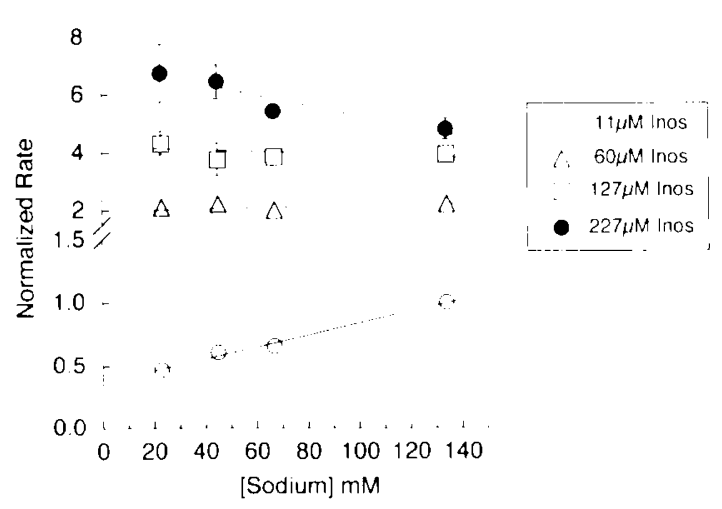

Fig. 4. Sodium dependence of the initial rate of myo-inositol uptake. The uptake of $m y\left(r-\left[2-{ }^{3} \mathrm{H}\right]\right.$ inositol by fibroblasts was measured for a $30-$ min period in media of varying sodium concentrations as in Figure 3. Rates were normalized to the average values of the samples in $134 \mathrm{mM}$ sodium and $11 \mu \mathrm{M}$ myo-inositol. Points are means \pm SEM for four to eight determinations; the lines are from a linear regression analysis of the data.

teristics of the fibroblasts may have been perturbed at the extreme medium sodium concentration of $23 \mathrm{mM}$. The uptake of myo$\left[2-{ }^{3} \mathrm{H}\right]$ inositol at $30 \mathrm{~min}$ in the presence of varying concentrations of sodium is shown in Figure 4. At myo-inositol concentrations near the $\mathrm{K}_{\mathbf{t}}$ for transport, sodium ion concentrations had little effect. At higher concentrations of myo-inositol, the initial rate of uptake was actually higher as the sodium concentration was decreased, whereas at $11 \mu \mathrm{M} m$ mo-inositol uptake appeared to have a dependence on sodium.

The inhibition of $m y o$-inositol uptake by phloridzin and phloretin is shown in Figure 5 as the Lineweaver-Burk transformations of the kinetic data. Phloridzin acted as a competitive inhibitor of myo-inositol uptake with a $\mathrm{K}_{\mathrm{i}}$ of approximately $60 \mu \mathrm{M}$. Phloretin, the aglycan form of phloridzin, proved to be an uncompetitive or noncompetitive inhibitor of my(r)-inositol uptake. The inhibition of myo-inositol uptake by glucose and galactose was determined in experiments using 11 to $200 \mu \mathrm{M}$ $m y$ o-inositol with 5-20 mM glucose or $5 \mathrm{mM}$ glucose and 5-15 $\mathrm{mM}$ galactose. Both glucose and galactose were only weak competitive inhibitors of uptake. With Lineweaver-Burk transfor- 

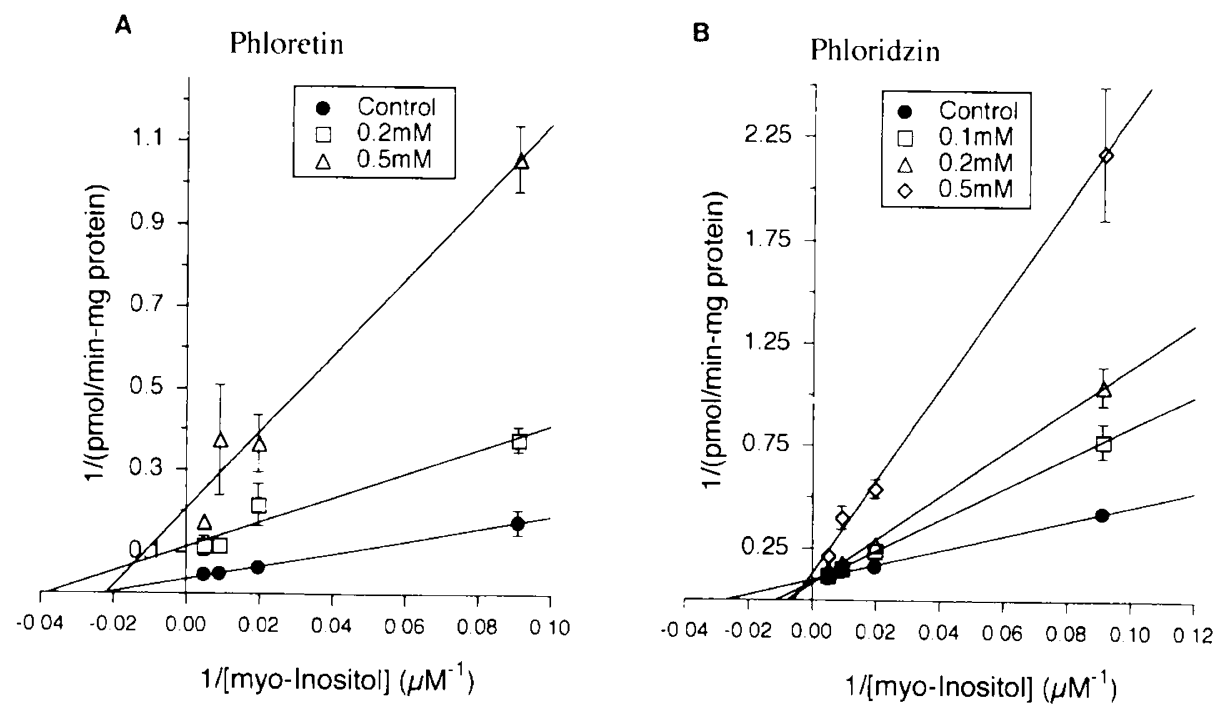

Fig. 5. Inhibition of myo-inositol uptake by phloretin and phloridzin. Fibroblasts were incubated with $m y \cdot 0-\left[2-{ }^{3} \mathrm{H}\right]$ inositol at concentrations ranging from 11 to $200 \mu \mathrm{M}$ with or without phloretin or phloridzin and the indicated concentrations. Points are means \pm SEM for four to eight determinations; the lines are from a linear regression analysis of the data after a double reciprocal transformation.

mations of the kinetic data, the $\mathrm{K}_{\mathrm{i}}$ of glucose and galactose was determined to be $30 \mathrm{mM}$ and $65 \mathrm{mM}$, respectively.

Fibroblasts were incubated for 0 to $48 \mathrm{~h}$ with $20 \mathrm{mM}$ glucose or $15 \mathrm{mM}$ galactose. The uptake of $m y o-\left[2-{ }^{3} \mathrm{H}\right]$ inositol and its incorporation into lipid were measured for 2 to $4 \mathrm{~h}$ after changing the medium to MEM without serum. Results of the uptake determinations, normalized to the control values obtained with normal MEM (5 mM glucose) on each day of the experiment, are presented in Table 1 . Neither sugar was a competitive inhibitor of myo-inositol uptake under the conditions studied. However, cells incubated in $20 \mathrm{mM}$ glucose for $24 \mathrm{~h}$ showed about a $10 \%$ inhibition of myo-inositol uptake from the same medium. and by $48 \mathrm{~h}$ a similar inhibition was observed in the galactose treated cells as well. Label incorporated into lipid simulated the same pattern as label in the supernatant.

Levels of myo-inositol were determined by gas-liquid chromatography in several lines of fibroblasts from donors 2 mo to $9 \mathrm{y}$ of age. Results for a given line were consistent and remained constant for 6 to 14 passages. Several of the determinations were performed in more than 15 separate experiments. In addition, little variation occurred in myo-inositol levels in a particular line regardless of whether the fibroblast extracts were prepared im- mediately or several hours after removal of the media with $20 \%$ FBS. As seen in Figure 6, although variability was observed from line to line, no obvious relationship with the age of the donor could be discerned. Ranging from $10-50 \mathrm{nmol} / \mathrm{mg}$ protein, the cell myo-inositol content varied by as much as 5-fold. No obvious relationship existed between cellular levels and the capacity for transport of myo-inositol.

We examined the effect of a 24-h incubation with elevated glucose or galactose on myo-inositol levels. Neither sugar had an effect on fibroblast myo-inositol levels (Table 2). Glucose at 20 $\mathrm{mM}$ had little effect on the fibroblast content of glucose and polyol. In contrast, galactose at only $5 \mathrm{mM}$ raised the cell content of galactose and polyol (galactitol) many fold but had no effect on the fibroblast $m y o$-inositol levels. Similar results were found after 48 and $72 \mathrm{~h}$ of incubation.

\section{DISCUSSION}

Human skin fibroblasts exhibited a high-affinity transport system for $m y o$-inositol with an apparent $\mathrm{K}_{\mathrm{t}}$ of $55 \mu \mathrm{M}$, which is near the normal serum concentration for myo-inositol in anyone other than a fetus or newborn infant. The rate of transport was

Table 1. Effect of preincubation with elevated sugar concentrations on fibroblast uptake of myo- $2-{ }^{3} \mathrm{H} /$ inositol and incorporation into phospholipid*

\begin{tabular}{|c|c|c|c|c|}
\hline \multirow[b]{2}{*}{ Exposure } & \multicolumn{2}{|c|}{ Uptake } & \multicolumn{2}{|c|}{ Incorporation } \\
\hline & Control & Glucose (20 mM) & Control & Glucose $(20 \mathrm{mM})$ \\
\hline \multirow{4}{*}{$\begin{array}{l}\text { None (8) } \\
24 \mathrm{~h} \mathrm{(12)} \\
48 \mathrm{~h}(8)\end{array}$} & $1.00 \pm 0.02$ & $1.05 \pm 0.03 \dagger$ & $1.00 \pm 0.03$ & $0.87 \pm 0.08 t$ \\
\hline & $1.00 \pm 0.05$ & $0.89 \pm 0.03 \ddagger$ & $1.00 \pm 0.01$ & $0.86 \pm 0.06 \ddagger$ \\
\hline & $1.00 \pm 0.01$ & $0.90 \pm 0.02 \S$ & $1.00 \pm 0.04$ & $0.84 \pm 0.02 \S$ \\
\hline & Control & Galactose (15 mM) & Control & Galactose (15 mM) \\
\hline None (4) & $1.00 \pm 0.04$ & $0.97 \pm 0.12 \dagger$ & $1.00 \pm 0.03$ & $0.90 \pm 0.14 \dagger$ \\
\hline $24 \mathrm{~h}(12)$ & $1.00 \pm 0.03$ & $0.93 \pm 0.05 \dagger$ & $1.00 \pm 0.02$ & $0.94 \pm 0.08 \dagger$ \\
\hline $48 \mathrm{~h} \mathrm{(12)}$ & $1.00 \pm 0.02$ & $0.90 \pm 0.04 \ddagger$ & $1.00 \pm 0.07$ & $0.94 \pm 0.04 \dagger$ \\
\hline
\end{tabular}

* Uptake of $11 \mu \mathrm{M}$ myo-inositol at 2 to $4 \mathrm{~h}$ was examined in fibroblasts exposed to the indicated media for 0 to $48 \mathrm{~h}$. The uptake was performed in the same media but without serum. Rates were calculated as picomoles per minute per milligram of protein and normalized to the average control values. The control medium was MEM containing $5 \mathrm{mM}$ glucose. Glucose media contained an additional $15 \mathrm{mM}$ glucose for a total of $20 \mathrm{mM}$ hexose. Galactose media contained $15 \mathrm{mM}$ galactose for a total of $20 \mathrm{mM}$ hexose. Statistical significance of differences was calculated by $t$ test. Results are the means \pm SEM for the number of determinations (in parentheses).

+ No statistical significance seen.

$\ddagger p<0.05$

$\S p<0.01$. 


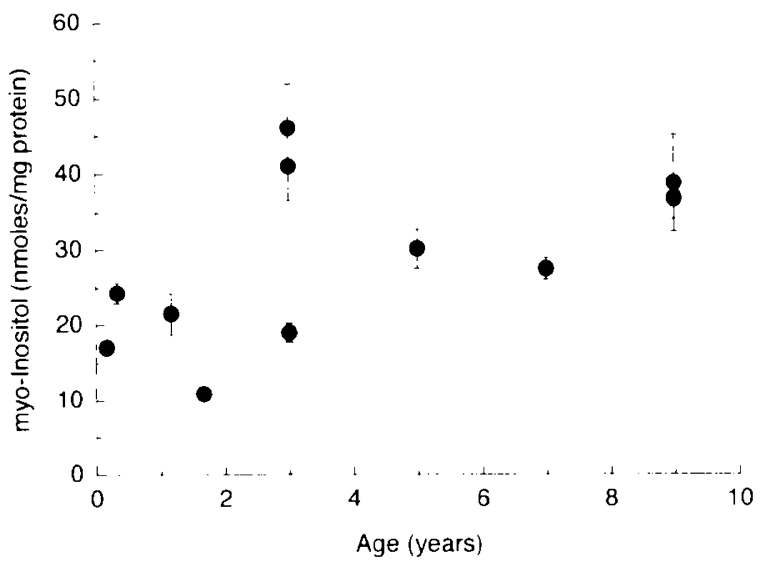

Fig. 6. Levels of myo-inositol in human skin fibroblasts from 11 donors of varying ages. Levels of myo-inositol were determined by gasliquid chromatography and are expressed as nanomoles per milligram of fibroblast protein. Each point represents a single cell line. Results are means \pm SEM for 2 to 17 determinations on each line.

Table 2. Effect of incubation with elevated sugar concentrations on fibroblast myo-inositol, polyol, and carbohydrate levels*

\begin{tabular}{lcccc}
\hline & \multicolumn{4}{c}{ Nanomoles per milligram of protein } \\
\cline { 2 - 5 } & Myo-inositol & Polyol & Glucose & Galactose \\
\hline Control & $34.6 \pm 1.9$ & $2.9 \pm 0.6$ & $31.4 \pm 2.1$ & $0.4 \pm 0.4$ \\
Glucose & $33.3 \pm 2.8$ & $5.3 \pm 2.6$ & $44.3 \pm 5.9$ & $0.8 \pm 0.5$ \\
Control & $46.1 \pm 4.2$ & $1.5 \pm 0.5$ & $31.4 \pm 2.1$ & $0.4 \pm 0.4$ \\
Galactose & $48.6 \pm 5.1$ & $17.5 \pm 1.9 \dagger$ & $44.4 \pm 6.1$ & $15.2 \pm 5.4 \ddagger$
\end{tabular}

* Fibroblasts were incubated in MEM with FBS for $24 \mathrm{~h}$. The final concentration of myo-inositol was $224 \pm 6 \mu \mathrm{M}$. In paired experiments, the control media contained $5 \mathrm{mM}$ glucose, whereas the experimental glucose media contained $20 \mathrm{mM}$ glucose and the experimental galactose media contained $5 \mathrm{mM}$ glucose and galactose. Carbohydrates were analyzed as trimethylsilyl derivatives by gas-liquid chromatography. The results presented are the means \pm SEM for 6 to 12 determinations.

+ Different from control at $p<0.001$

¥ Different from control at $p<0.05$.

low, and the cells had not achieved isotopic equilibrium with the medium $m y o-\left[2-{ }^{3} \mathrm{H}\right]$ inositol by $24 \mathrm{~h}$ of incubation; the calculated $\mathrm{V}_{\max }$ was about $16 \mathrm{pmol} / \mathrm{min} / \mathrm{mg}$ protein. Transport systems for myo-inositol with similar kinetic parameters have been observed in many mammalian tissues (21-26) and in cells in culture (8$12,18,27-29)$. Studying fibroblasts during active cell division or in the nonconfluent state, Fruen and Lester (17) described a high-affinity sodium-dependent myo-inositol transport system with an apparent $\mathrm{K}_{t}$ of $35.4 \mu \mathrm{M}$ and $\mathrm{V}_{\max }$ of $5.8 \mathrm{pmol} / \mathrm{min} / \mathrm{mg}$ protein. Both phloretin and its glycosylated analogue phloridzin inhibited the uptake of myo-inositol. Phloretin acted as an uncompetitive or noncompetitive inhibitor, whereas phloridzin had a $\mathrm{K}_{\mathrm{i}}$ of about $60 \mu \mathrm{M}$, similar to the $\mathrm{K}_{\mathrm{t}}$ for myo-inositol. Glucose and galactose were very weak competitive inhibitors, with a $\mathrm{K}_{\mathrm{i}}$ of 30 and $65 \mathrm{mM}$, respectively.

The sodium dependence of myo-inositol uptake was somewhat complex. Using 30-min incubations to assess the initial rate of myo-inositol transport, we found a weak dependency on sodium concentration only at $11 \mu \mathrm{M} m y o$-inositol. At myo-inositol concentrations above $200 \mu \mathrm{M}$, the initial rate of uptake was actually higher at $23 \mathrm{mM}$ sodium. When the time course of myo-inositol uptake was examined in media with varying sodium concentrations, we found that uptake ceased after about $1 \mathrm{~h}$ at the lowest sodium concentration of $23 \mathrm{mM}$. A time-dependent decline in the transport rate for myo-inositol under low sodium conditions was also observed in rat Schwann cells (27).

On repeated subculturing in media containing more than 200 $\mu \mathrm{M}$ myo-inositol, the human skin fibroblasts contained $10-50$ nmol myo-inositol/mg protein. Considerable variability existed among cell lines, but each line maintained a constant myoinositol level with passage. The different cell lines showed little variation in the rate of myo-inositol uptake, and thus no correlation, positive or negative, existed between transport capacity and cellular levels of myo-inositol. This finding is somewhat surprising and suggests that other factors, perhaps of a genetic nature, help to regulate the cell content of mivo-inositol. Although the synthetic rates still must be measured in different fibroblast lines, we believe that these variations are not due to myo-inositol synthesis. Even cells whose survival depends on the availability of $m v o$-inositol as an intracellular osmolyte fail to use de novo synthesis in the regulation of levels (29). The stability of myoinositol levels within our cell lines is further supported by the fact that little intraexperimental or interexperimental variation occurred in measured uptake, whether time or my'o-inositol concentration dependent, for a particular cell line despite abrupt declines in ambient myo-inositol concentrations as the cells were routinely switched to serum-free media for study. Although the rates of uptake are not of the same magnitude as other solute transport systems, the uptake data suggest that at a normal serum myo-inositol concentration of $50 \mu \mathrm{M}$. fibroblasts would exchange about one third of their myo-inositol with the medium in $24 \mathrm{~h}$. The incorporation of $m y o-\left[2-{ }^{3} \mathrm{H}\right]$ inositol into phospholipid paralleled its uptake into the cell. Essentially no label was found in membranes for the first $30 \mathrm{~min}$ of incubation, and incorporation continued in a linear fashion after the uptake had leveled off. Even after $24 \mathrm{~h}$, the label in lipid was only about $10 \%$ that in the myo-inositol pool.

The response of human skin fibroblasts to elevated levels of glucose is of interest because they may be involved in alterations of the skin seen in diabetic patients in the enigmatic diabetic connective tissue syndromes $(30,31)$. Apropos of the question of whether high blood glucose levels induce pathologic effects on the fibroblast, Turner and Bierman (32) had previously shown that cultured fibroblasts exposed to $10-20 \mathrm{mM}$ glucose manifested an up-regulated cell proliferative response to FBS. Importantly, however, these mesodermal elements differ from many of the other cells or tissues conspicuously involved in diabetic complications or previously shown to be affected by high sugar levels in vitro in that they possess a system for glucose transport that is both of low capacity and, albeit weakly, insulin dependent $(33,34)$. Thus, we would not expect elevated medium glucose levels to result in a significant elevation of intracellular-free glucose and sorbitol. Further, glucose has not been found to be a strong competitive inhibitor of myo-inositol transport in human skin fibroblasts (17). In contrast, our experiments, as well as other studies (18), show that human skin fibroblasts readily take up galactose and convert it to galactitol.

We examined the effects of a 24- or 48-h exposure of human skin fibroblasts to elevated sugar concentrations. Raising the medium glucose concentration to $20 \mathrm{mM}$ for $24 \mathrm{~h}$ had little effect on intracellular carbohydrate levels. The increase in cellular glucose and polyol did not achieve statistical significance. In contrast, fibroblasts incubated in normal MEM supplemented with only $5 \mathrm{mM}$ galactose accumulated free galactose and polyol to a level 10 or more times that in control cells. Neither elevated glucose nor galactose in the presence of more than $200 \mu \mathrm{M} \mathrm{myo-}$ inositol had an effect on the cellular myo-inositol levels during this time period.

In other experiments, the uptake and incorporation of myoinositol for 2 to $4 \mathrm{~h}$ was examined in the presence of $20 \mathrm{mM}$ glucose or $15 \mathrm{mM}$ galactose. Neither sugar inhibited the uptake of myo-inositol when it was presented only during the 2- to 4-h incubation period. This finding is not surprising given the weak competitive effect of glucose or galactose observed in $30-\mathrm{min}$ transport experiments. However, cells incubated with $20 \mathrm{mM}$ glucose for $24 \mathrm{~h}$ showed a small decrease in myo-inositol uptake. After $48 \mathrm{~h}$, both sugars appeared to reduce myo-inositol uptake 
and metabolism. It might be expected that this effect was not related to accumulation of polyol because incubation with galactose produced much greater polyol accumulation but no greater inhibition of myo-inositol transport. Furthermore, because the effect on uptake was "delayed" and yet neither sugar was a significant competitive inhibitor of transport, this effect may not be related to competitive inhibition. In addition, this unexplained diminution in myo-inositol uptake may not even be dependent on intracellular glucose or galactose levels. Time may be a key factor in the full expression of sugar toxicity. For example, Okuda et al. (35) showed that chronic exposure to extremely high concentrations of glucose, i.e. subculturing fibroblasts in media with 28 and $55 \mathrm{mM}$ glucose, albeit in the presence of mvoinositol in excess of $150 \mu \mathrm{M}$, resulted in reduced uptake of 50 $\mu \mathrm{M}$ myo-inositol that was partially polyol pathway dependent.

Our data show that prolonged exposure of human skin fibroblasts to elevated glucose or galactose concentrations resulted in a modest reduction in myo-inositol transport when they were subsequently studied at a concentration of myo-inositol typical of the adult organism. Furthermore, this reduction was detected even though the concentration of myo-inositol in the FBSsupplemented media had been in excess of $200 \mu \mathrm{M}$. The physiologic significance of this effect remains to be determined. It may be a singular manifestation of a more generalized defect in membrane function. If found to be significant despite no detectable reduction in cell myo-inositol levels, it would support the concept that persistent elevation of extracellular hexose interferes with the maintenance of a small pool of myo-inositol important in cell metabolism $(5,36)$. It is unclear why fibroblast my()inositol content varies by as much as 5-fold in the different cell lines and provokes the consideration of how relevant the measurement of total cell myo-inositol is to fibroblast metabolism. Molitoris et al. (37) suggested that myo-inositol is largely sequestered or bound in skeletal muscle tissue. Several investigators have also alluded to the presence of more than one pool of $m y$ inositol in certain cells or tissues $(23,38,39)$. Despite millimolar levels of myo-inositol in cells, only micromolar concentrations may be sufficient for optimal membrane phosphatidylinositol biosynthesis $(23,40,41)$. We recently provided kinetic evidence to support a hypothesis that the cytosolic concentration of unbound metabolically active myo-inositol in the hepatocyte is closer to the extracellular concentration than the total measurable level (42). A similar physiologic condition might pertain to the fibroblast, with variations in total levels in different cell lines being related to genetic factors that affect $m v o$-inositol sequestration within organelles or binding to macromolecules. It is clear that any new insight into the effects of sugar toxicity on myoinositol metabolism is dependent on a better understanding of myo-inositol metabolism per se. Human skin fibroblasts in culture may provide a unique system for dissociating the effects of hexose and polyol toxicity on cell metabolism.

\section{REFERENCES}

1. Berrtidge MJ, Irvine RF 1989 Inositol phosphates and cell signalling. Nature 341:197-205

2. Nishizuka $Y 1984$ Turnover of inositol phospholipids and signal transduction. Science 225:1365-1370

3. Dawson RMC, Freinkel N 1961 The distribution of free mesorinositol in mammalian tissues, including some observations on the lactating rat. Biochem J 78:606-610

4. Lewin LM, Yannai Y. Sulimovici S, Kraicer PF 1976 Studies on the metabolic role of myo-inositol. Distribution of radioactive my-inositol in the male rat. Biochem J 156:375-380

5. Winegrad AI 1986 Does a common mechanism induce the diverse complications of diabetes? Diabetes 6:396-406

6. Green DA, Lattimer SA, Sima AAF 1987 Sorbitol, phosphoinositides, and sodium-potassium-ATPase in the pathogenesis of diabetic complications. N Engl J Med 316:599-606

7. Li W. Chan LS. Khatami M. Rockey JH 1986 Non-competitive inhibition of myo-inositol transport in cultured bovine retinal capillary pericytes by glucose and reversal by sorbinil. Biochim Biophys Acta 857:198-208

8. Yorek MA. Dunlap JA, Ginsberg BA 1987 M 1 ( $/$-inositol metabolism in 41 A. 3 neuroblastoma cells: effects of high glucose and sorbitol levels. J Neurochem 48:53-61

9. Khatami M. Rockey JH 1988 Regulation of uptake of inositol by glucose in cultured retinal pigment epithelial cells. Biochem Cell Biol 66.951-957

10. delMonte MA, Rabbani R, Diaz. TC, Lattimer SA. Nakamura J, Brennan MC, Greene DA 1991 Sorbitol, myr-inositol, and rod outer segment phagocytosis in cultured hRPE cells exposed to glucose. Diabetes 40:1335-1345

11. Yorek MA. Dunlap JA 1989 The effect of elevated glucose levels on myor inositol metabolism in cultured bovine endothelial cells. Metabolism 38:1622

12. Haneda M. Kikkawa R. Arimura T, Ebata K. Togawa M, Maeda S. Sawada T. Horide N. Shigeta Y 1990 Glucose inhibits myo-inositol uptake and reduces my'rinositol content in cultured rat glomerular mesangial cells. Metabolism 39:40-45

13. Sussman I, Carson MP. Schultz V. Wu XP. McCall AL, Ruderman NB. Tornheim K 1988 Chronic exposure to high glucose decreases murrinositol in cultured cerebral microvascular pericytes but not in endothelium. Diabetologia 31:771-775

14. Yorek MA. Dunlap JA, Leeney EM 1989 Effect of galactose and glucose levels and sorbinil treatment on mir(-inositol metabolism and $\mathrm{Na}^{+}-\mathrm{K}^{+}$pump activity in cultured neuroblastoma cells. Diabetes 38:996-1004

15. Stewart MA, Kurien MM. Sherman WR. Cotlier EV 1968 Inositol changes in nerve and lens of galactose fed rats. J Neurochem 15:941-946

16. Loy A, Lurie KG, Ghosh A, Wilson JM. MacGregor LC. Matschinsky FM 1990 Diabetes and the myo-inositol paradox. Diabetes 39:1305-1312

17. Fruen BR, Lester BR 1990 Down's syndrome fibroblasts exhibit enhanced inositol uptake. Biochem J 270:119-123

18. Schaub J, Shin-Buehring Y. Wiese B, Rahm P. Haas B 1979 Metabolism of galactose and accumulation of galactose-1-phosphate in various cell types of cultured fibroblasts for galactosemia. In: Hommes FA (ed) Models for the Study of Inborn Errors of Metabolism. Elsevier/North-Holland Biomedical Press. Amsterdam, pp 319-327

19. States B. Harris D. Segal S 1974 Uptake and utilization of exogenous cystine by cystinotic and normal fibroblasts. J Clin Invest 53:1003-1016

20. Lowry OH, Rosebrough NJ, Farr AL, Randall RJ 1951 Protein measurement with the Folin phenol reagent. J Biol Chem 193:265-275

21. Cotlier E $1970 M / y(-$-inositol: active transport by the crystalline lens. Invest Ophthal 9:681-691

22. Spector R. Lorenzo AV 1975 Myrinositol transport in the central nervous system. Am J Physiol 228:1510-1518

23. Hallman M, Slivka S, Wozniak P. Sills J 1986 Perinatal development of myre inositol uptake into lung cells: surfactant phosphatidylglycerol and phosphatidylinositol synthesis in the rabbit. Pediatr Res 20:179-185

24. Greene DA, Lattimer SA 1982 Sodium- and energy-dependent uptake of myra inositol by rabbit peripheral nerve. J Clin Invest 70:1009-1018

25. Biden TJ, Wollheim CB 1986 Active transport of mv'r-inositol in rat pancreatic islets. Biochem J 236:889-893

26. Ohga Y, Nishijima M, Akamatsu Y 1990 Chinese hamster ovary cell mutants defective in myo-inositol transport. J Biol Chem 265:18083-18086

27. Segal S, Hwang S-M, Stern J, Pleasure D 1984 Inositol uptake by cultured isolated rat Schwann cells. Biochem Biophys Res Commun 120:486-492

28. Yorek MA, Dunlap JA, Ginsberg BM 1986 M (rinositol uptake by four cultured mammalian cell lines. Arch Biochem Biophys 246:801-807

29. Nakanishi T, Turner RJ, Burg MB 1989 Osmoregulatory changes in myoinositol transport by renal cells. Proc Nat Acad Sci USA 86:6002-6006

30. Lundbaek K 1957 Stiff hands in long-term diabetes. Acta Med Scand 158.44745 !

31. Grgic A, Rosenbloom AL, Weber F 1976 Joint contracture-common manifestation of childhood diabetes mellitus. J Pediatr 88:584-588

32. Turner JL. Bierman EL 1978 Effects of glucose and sorbitol on proliferation of cultured human skin fibroblasts and arterial smooth-muscle cells. Diabetes 27:583-588

33. Howard BV, Mott DM. Fields RM. Bennett PH 1979 Insulin stimulation of glucose entry in cultured human fibroblasts. J Cell Physiol 101:129-138

34. Berhanu P. Olefsky JM 1981 Effects of insulin and insulin-like agents on the glucose transport system of cultured human fibroblasts. Diabetes 30:523529

35. Okuda Y, Bannai C, Nagahama M. Isaka M Yamashita K 1991 Restoration of myo-inositol uptake by aldose reductase inhibitor in human skin fibroblasts cultured in high-glucose medium. Horm Metab Res 23:42-43

36. Zhu X. Eichberg J 1990 Mroinositol pool utilized for phosphatidylinositol synthesis is depleted in sciatic nerve from rats with streptozotocin-induced diabetes. Proc Nat Acad Sci USA 87:9818-9822

37. Molitoris BA, Karl IE, Daughaday WH 1980 Concentration of myo-inositol in skeletal muscle of the rat occurs without active transport. J Clin Invest 65:783-788

38. Hauser G, Eichberg J 1976 Accumulation and metabolism of phosphatidy]CMP (CDP-diglyceride) in the pineal gland of the rat. In: Porcellati G, 
Amaducci L, Galli C (eds) Function and Metabolism of Phospholipids in the Central and Peripheral Nervous System. Plenum, New York, pp 149158

39. Diringer $H$, Rott $R 1977$ Different pools of free mvo-inositol in chick embryo cells as indicated by infection with Newcastle disease virus. Eur J Biochem 79:451-457

40. Freinkel N, El Younsi C, Dawson RMC 1976 Inter-relations between the phospholipids of rat pancreatic islets during glucose stimulation and their response to medium inositol and tetracaine. Eur J Biochem 59:245-252

41. Bleasdale JE, Tyler NE, Busch FN, Quirk JG 1983 The influence of $m y 0$ inositol on phosphatidylglycerol synthesis by rat type II pneumocytes. Biochem J 212:811-818

42. Sigal SH, Yandrasitz JR, Berry GT 1993 Kinetic evidence for compartmentalization of myo-inositol in hepatocytes. Metabolism 42:395-401

\section{Announcement}

The Society for Behavioral Pediatrics will conduct its 12th Annual Scientific Meeting and Workshops on September 22-26, 1994 at the Marriott City Center in Minneapolis. MN. For further information and registration forms, please contact Ms. Noreen Spota at (215) 248-9168. 